\title{
DO THE FAMA AND FRENCH FIVE-FACTOR MODEL FORECAST WELL USING ANN?
}

\author{
Muhammad Naveed JAN ${ }^{1^{*}}$, Usman AYUB $^{2}$ \\ ${ }^{1}$ Department of Management Sciences, Capital University of Science and Technology, \\ Islamabad, Pakistan \\ ${ }^{2}$ Department of Management Sciences, COMSATS University Islamabad, Pakistan
}

Received 28 November 2018; accepted 10 December 2018

\begin{abstract}
Forecasting the stock returns in the emerging markets is challenging due to their peculiar characteristics. These markets exhibit linear as well as nonlinear features and Conventional forecasting methods partially succeed in dealing with the nonlinear nature of stock returns. Contrarily, Artificial Neural Networks (ANN) is a flexible machine learning tool which caters both the linear and nonlinear markets. This paper investigates the forecasting ability of ANN by using Fama and French five-factor model. We construct ANN's based on the composite factors of the FF5F model to predict portfolio returns in two stages; in stage one, the study identifies the best-fit combination of training, testing, and validation along with the number of neurons full sample period. In stage two, the study uses this best combination to forecast the model under 48-months rolling window analysis. In-sample and out-sample comparisons, regression, and goodness of fit test and actual and predicted values of the stock returns of our ANN model reveal that the proposed model accurately predicts the one-month ahead returns. Our findings reinforce the investment concept that the markets compensate the high-risk portfolios more than mid and low beta portfolios and the methodology will significantly improve the return on investment of the investors.
\end{abstract}

Keywords: artificial neural networks, forecasting, Fama and French 5 Factors CAPM, asset pricing models, stock markets.

JEL Classification: C18, C45, C63, G12, G17.

\section{Introduction}

The stock markets spur the economic development of a country thus playing a pivotal role in shaping and growth of the economies (Bonfiglioli, 2008; Levine, 2008). The magnitude of investments in stock markets worldwide provide evidence that the stock markets mobilize massive investments and many emerging economies develop a strong foundation for economic development through these markets (Bekaert, Harvey, \& Lundblad, 2005; Levine, 2008). The

*Corresponding author. E-mail: naveedjan20005@gmail.com 
stakeholders of the stock markets are always interested in forecasting to magnify their returns on investment. The researchers and academicians help these stakeholders in finding innovative forecasting models which can explain the mechanics of the equity markets.

Forecasting the stock returns, on the other hand, is challenging and (Oztekin, Kizilaslan, Freund, \& Iseri, 2016) provide evidence that even the application of innovative financial modeling return partially successful results. Malkiel (2011) notes that the actual returns of the individual investors both in the emerging and developed stock markets are low as compared to the average market returns. Karaban and Maguire (2012), however, find that some investors in the same markets and particular situations earn above the market returns. Gray, Steinfort, and McIntosh (2012) mention many reasons for these nonsynchronous returns. It includes; the lack of the use of the latest mathematical and statistical forecasting techniques by the researchers, the use of random technical and financial variables instead of established asset pricing models and the inability of the researchers to test their models in the actual environment of the markets.

Artificial Neural Networks can revitalize the pricing of risky assets and enable investors to organize their investments in a profitable way (Sonsino \& Shavit, 2014). The asset pricing models have played a vital role in enhancing the portfolio returns and these models are a central theme of the investment and portfolio decision making (Malkiel, 2011). These models are based on the linear risk and return relationship assuming normal or log-normal distributions of asset returns for a rational investor. Practicallty, it is difficult to find such stock markets, especially in volatile environments, to qualify for these assumptions. In the real world setting these simple assumptions need to be modified (McMillan, 2003; McNelis, 2005). Artificial Neural Networks is a sub-discipline of Artificial intelligence. It is a nonparametric and nonlinear technique and has received the attention of researchers in finance and economics in recent years. The salient feature of the artificial neural networks is that it captures the last moment changes in the financial variables up to a certain level, which can alter the decision making of the investors (Quah, 2008). The mechanism and algorithm of artificial neural networks closely resemble the human brains in processing information and decision making (Rojas, 2013).

The forecasting performnace of ANN in capital markets is evidenced by many conferences and a vast repository of literature in the last two decades. Recent applications of ANN's in stock market forecasting also provide strong support for the successful prediction of nonlinear markets. See for example (Guan, Dai, Zhao, \& He, 2018; A. H. Moghaddam, M. H. Moghaddam, \& Esfandyari, 2016; Qiu \& Song, 2016; Vortelinos, 2017; L. Wang, Z. Wang, Zhao, \& Tan, 2015; Zahedi \& Rounaghi, 2015). The shortcomings of these studies is firstly the selection of input variables based on the researcher's choice but not supported by the establsihed asset pricing models, secondly these studies concentrate on the forecasting of index movement and the interpretation of the index movements in terms of investors returns is possible in those markets only where index derivatives are available. Thirdly the use of the limited options of datasets and finally most of these studies utilized the generic software of ANN with limited options. The long-term portfolio investors, on the other hand, mainly rely on the composite factors of asset pricing models for forecasting their returns mainly due to its generalization ability in the global markets. This difference in investment strategies of the 
day traders and long-term investors is the main drawback of ANN literature on forecasting in stock markets.

The purpose of our study is to investigate the forecasting ability of Artificial Neural Networks from broad horizons including the parameters of the Artificial Neural Networks by using the composite factors of asset pricing models. Specifically, we apply Artificial Neural Networks algorithms to the Fama and French five-factor (FF5F) model in Pakistan's equity markets. The time series of stocks returns is measured by the financial factors of the five factors models. The present study makes a contribution to the research in asset pricing by addressing the aforementioned problem; "Can the Artificial Neural Networks methodology be applied to the discipline of asset pricing to generate economic significance for the investors in the emerging markets"? The solution to this problem is expected to solve the major concern of investors to overcome the uncertainty of the Equity markets in emerging countries and generate significant economic value.

Some notable studies in applying Artificial Neural Networks to asset pricing models are those of (Cao, Leggio, \& Schniederjans, 2005; Cao, Parry, \& Leggio, 2011; Gokgoz \& Sezgin-Alp, 2014). These studies report that the neural networks along with Capital asset pricing model (CAPM) and Fama and French three-factor model (FF3F) provide a valuable linkage of the asset pricing theory with ANN and report significant improvement in the prediction performance of ANN in the long run. These studies suffer from certain limitations including the limited number of neurons used, inadequate datasets of training, testing and validation, the period of the study and the number of observations. Furthermore, these investigations are not updated as a recent addition in the form of the Fama and French five-factor model. Our study is based on the established composite factors of a major asset pricing model with the broad testing horizons of the Artificial Neural Networks and concentrating on portfolio returns, thus making this study comprehensive and pioneering in the emerging markets.

In section 1, we include the relevant literature on the basic concepts of Artificial Neural Networks and its forecasting ability in stock markets. Section 2 discusses the period of the study, the data sources and the salient features of the Pakistan Stock Exchange. This section also elaborates the methods of constructing the relevant portfolios of Fama and French five factors mode and presents the Artificial Neural Networks (ANN) model building regarding the multifactor asset pricing models, data distribution technique, the number of hidden layers and neurons, the performance evaluation technique and other details. The results constructed by ANN and multi-factor models are presented in section 3. In section 4, we discuss the results, and finally, Conclusions are drawn from the results. The conclusion section also provides practicable guidelines on the application of ANN in other aspects of asset pricing.

\section{Literature review}

The financial modeling in the stock markets is, in fact, the modeling of the investor's thinking and most of the time, this thinking is not rational (Sargent, 1993). Even the availability of all the public and private information is not the guarantee that the investment decisions would be balanced, and the investors have to learn the changing factors and the nonlinear nature 
of stock markets on the spot (Kamruzzaman, 2006). The algorithms of Artificial Neural Networks behave like humans in decision-making and demonstrate excellent ability to learn the input-output relationship of the target dataset without knowing the underlying assumptions on which a dataset is based (Franses \& Van Dijk, 2000). The mathematical modeling of the human brain in this way has revolutionized the contemporary decision making and industrial processes (Carvalhal \& Ribeiro, 2008; Tkáč \& Verner, 2016). The difference in speed and accuracy in human thinking is attributed to the availability of billions of neurons in the human beings (Staub, Karaman, Kaya, Karapınar, \& Güven, 2015) while the Artificial Neural Networks rely on the precision of mathematical equations and the speed of the electronic gadgets.

ANN's are nonlinear techniques which make them more suitable for capturing the relationships of noisy and nonlinear environments like stock markets (Franses \& Van Dijk, 2000). ANN's are considered as a modified form of STAR family ${ }^{1}$ (Smooth Transition Autoregressive) models by Econometricians. The STAR models demonstrate a higher degree of flexibility in modifying the parameters of models (Franses \& Van Dijk, 2000). This view regarding the recognition of ANN's as an extension of STAR models is a challenging question for other disciplines. The applications in finance also have numerous challenges because a thorough understanding of ANN requires a solid background in Physics and Statistical Mechanics, Computer Science, Artificial Intelligence, Control Theory, and Mathematics, etc. This reveals that the application of ANN requires interdisciplinary research ventures to model the financial markets successfully. The ANN is applied in economics and Finance on the pretext that access to information and time to process that information is limited. This challenge is considered as bounded rationality (Sgroi \& Zizzo, 2007). Specifically, the hypothesis of bounded rationality refers to the mathematical representation of the investor's expectation about their rate of returns (Liang, Yang, \& Cai, 2017).

The forecasting ability of the Neural Networks has attracted the attention of researchers since last two decades and a vast repository of literature is present which provide evidence of the significant forecasting ability of ANN in stock markets. The earlier studies concentrated on the stock market indices and applied numerous technical and financial variables to open the research vistas for ANN in capital markets forecasting (see for example, Armano, Marchesi, \& Murru, 2005; Gonzalez Miranda \& Burgess, 1997; Lendasse, de Bodt, Wertz, \& Verleysen, 2000; Majhi, Panda, \& Sahoo, 2009; O’Connor \& Madden, 2006). The employment of the fundamental variables in the ANN environment by various studies include Stock returns, trading volume, and dividends (Kanas \& Yannopoulos, 2001), Exchange rates (Walczak, 2001), Accounting ratios (Olson \& Mossman, 2003), Portfolio optimization (Ko \& Lin, 2008).

In the recent past, the distinguished sphere applications of ANN are (Maknickiene \& Maknickas, 2013a) choosing the exchange rates of various currencies and gold prices, (Dixit \& Roy, 2013) using the index prices, (Fadlalla \& Amani, 2014) employing various moving averages of the index price, (Zahedi \& Rounaghi, 2015) applying accounting variables, (Wang

\footnotetext{
1 Threshold Autoregressive (TAR) is a nonlinear model first introduced by (Chan \& Tong, 1986; Tong, 1978; Tong \& Lim, 1980) used this model as regime switching model and after that other authors changed some of its parameters to develop self-exciting TAR ( SETAR model) and Logistic STAR (LSTAR models (Franses \& Van Dijk, 2000).
} 
et al., 2015) using daily index prices, (Moghaddam et al., 2016) applying various lags of index prices, (Qiu \& Song, 2016) using important financial and macroeconomic variables, (Jabbari \& Fathi, 2014) applying the index prices and various types of moving averages, (Vortelinos, 2017) utilizing various technical and fundamental variables, (Guan et al., 2018) implementing ANN in the index prices; All these studies provide evidence that ANN's present better and sound forecasting performance in stock markets.

The comparative analysis of the forecasting ability of ANN and traditional models also provide evidence that ANN is a formidable challenge for the traditional techniques. An earlier study by (Donaldson \& Kamstra, 1997) compares ANN with GARCH-family models on various stock indices. The study finds ANN to be the best performing model as compared to GARCH, EGARCH, and GJR models. The study points out an important conclusion regarding the overfitting nature of ANN and concludes that the better forecasting ability of ANN is not due to ANN overfitting to dataset but its flexibility to capture the underlying nature of data. Similarly, (Jabbari \& Fathi, 2014) provide a comparative analysis of the least square regression and $\mathrm{ANN}$ in predicting the excess returns and find empirical evidence for the strong predictive power of ANN as compared to the regression tool.

Some studies have attempted to hybridize ANN with traditional techniques in anticipation of better forecasting results A foreign exchange forecasting model based on artificial neural works combined with Delphi evaluation technique presented by (Maknickienė \& Maknickas, 2013b) find ANN as a useful tool for the investors to make their portfolio construction process more profitable. Similarly, a recent study by (Qiu \& Song, 2016) proposes a hybrid approach for predicting the returns on an index by using a large number of predictive financial variables. Aforementioned is a rich study regarding ANN modeling but lacks the generalization ability due to a large number of randomly selected variables. The forecasting and classification ability of ANN in the credit transactions of Banks is investigated recently by Guotai, Abedin, and Moula (2017). This study utilizes various dataset combinations along with a series of hidden layer neurons and suggests that the proposed model is a serviceable tool in the hands of managers to classify the credit applicants.

Some important articles have provided meaningful guidelines for our study; for example, the investigation by (Stansell \& Eakins, 2004) is perhaps the first study to apply fundamental variables of the asset pricing models including the Market capitalization, Dividend Yield, $\mathrm{P} / \mathrm{S}$ ratio, $\mathrm{P} / \mathrm{E}$ ratio, and $\mathrm{P} / \mathrm{B}$. The study finds that $\mathrm{ANN}$ can be utilized to select portfolios which ensure superior investment returns than the benchmarks. The short-term predictive performance of artificial neural networks is examined by (Fadlalla \& Amani, 2014). The study finds evidence that the one day ahead forecasting of the index is closer to the actual closing price. The findings of these studies suggest that the prediction performance of ANN is not only surpassing the traditional methods; the analytical results of ANN are also better than most of the conventional and other nonlinear techniques. The use of ANN in Pakistan Equity Market is limited and some past studies taken up by (Danial, Noor, Usmani, \& Zaidi, 2008; Fatima \& Hussain, 2008; Haider \& Nishat, 2009; Iqbal, 2013). These studies mainly investigate the behavior of index movement in this market. The primary shortcoming of these studies is the missing link between ANN and investment significance for the investors. 
It should be noted, however, that the implementation of the neural networks cannot ignore the inherent drawbacks of this technique. The understanding of the parameters of ANN and the inability of ANN to describe the features of the estimated model are the major drawbacks of this technique. It is sometimes difficult to interpret the values of the parameters and due to these reasons ANN's are considered as the "black box". It is difficult to offer any explanation beyond the forecasting ability of the ANN to capture "hidden" relationships between input and output variables (Franses \& Van Dijk, 2000). Another problem is the phenomenon of over fitting mentioned by variables (Franses \& Van Dijk, 2000). Once a model is selected and trained on the training dataset, its performance is judged by the testing dataset since the network model is biased towards the training data and this creates the problem of over-fitting the data. When the error terms for the validation and testing Datasets have wide variations, the model is considered to be overfitting and is of little use for an investment purpose (Rechenthin, 2014).

Similarly, the application of ANN's does not translate always into better prediction results. Some researchers find simple linear forecasting time series models to produce better forecasting results as compared to ANN. Recently, Hossain and Nasser (2011) compare the forecasting performance of ARMA, GARCH, and artificial intelligence techniques and conclude that the traditional techniques outperform the neural networks and support vector machines in determining the direction of the index. Fescioglu-Unver and Tanyeri (2013) find that the performance of the multinomial logit model surpasses the ANN in forecasting the bidder firms. Similarly, Catik and Karaçuka (2012) find that traditional techniques of the ARFIMA and ARIMA provide better one-step ahead forecasting performance as compared to ANN and (Vortelinos, 2017) also report weak performance of ANN as compared to GARCH.

\section{Data and methodology}

We use Pakistan Stock Exchange as the universe and the sample firms include companies from the manufacturing sector listed on Pakistan Stock Exchange (PSX), previously known as (Karachi Stock Exchange), following (Fama \& French, 2015). Pakistan's equity market has attracted massive investments in recent years from all parts of the country, reaffirming the confidence of the people in the bourse's markets (Ghufran, Awan, Khakwani, \& Qureshi, 2016). Better infrastructural changes and automation of the primary processes have been introduced and most of the financial sector reforms in Pakistan including the stock market have taken place during the decade of 90's. The market is closely resembling the developed markets in terms of investor's education and information, analytical reports, Market trends and online trading system (Munir, Chaudhry, \& Akhtar, 2013). The Bloomberg's report by Kim and Mangi (2016) categorizes Pakistan's equity market as a significant market. The cumulative market capitalization of all the listed Companies is approximately $\$ 87$ Billion with 379.1 million average daily turnover of shares (State Bank of Pakistan, 2015). The listed capital witnessed a growth rate of $5.8 \%$ while the market capitalization demonstrated a $21 \%$ growth rate in the last five years.

Due to these reasons, we have selected the last fifteen years and use the data from January 01,2000 to December 2015 to gauge the application of the latest processing techniques 
in this emerging market. The data sources include Thompson Reuters DataStream and State Bank of Pakistan. We take the data for all the closing prices of stocks listed on the Pakistan Stock Exchange (PSX). Likewise, a proxy for market portfolio used in CAPM based models is taken as the closing PSX index as the standard procedure following Ayub, Shah, and Abbas (2015). Stock prices and PSX index is converted into returns ignoring the dividends, using $\log$ difference returns. The impact of dividends is emulated by the stock prices according to Ahmed and Javid (2008). We divide the sample Firms into 30 portfolios based on high, mid and low betas ${ }^{2}$ of the sample Firms.

The Fama and French (2015) relate the investment and profitability factors with the average stock returns of the investors. The significant finding of the Fama and French (2015) is that the five-factor model is useful in explaining the cross-sectional variations of the expected return. The explanatory power of the five factors model is more than $80 \%{ }^{3}$. However, a recent study by Racicot and Rentz (2016) uses the improved GMM-based robust instrumental variables technique to evaluate the FF5F model. The study finds that the market returns are sufficient to explain the variation in portfolio returns of the investors and all other factors are redundant. Our study is concentrating on the forecasting ability of the five factors model and the testing of the FF5F model in our sample market is out of the scope of the present study. The construction of the market returns, size, value, investment, and profitability factors use the financial variables of market capitalization, the book-tomarket ratio ( $\mathrm{B} / \mathrm{M}$ ratio), change in total assets and earnings before interest and taxes (EBIT) to total equity as proxies for the FF5F model following Fama and French (2015). For each company, the returns are sorted first by the total market capitalization from smallest to largest and split into two equal halves small (S) and big (B) sized firms respectively. After the first sort, each group of stocks are again sorted by the book to market ratio (B/M) and then distributed into three groups low $(\mathrm{L})$, medium $(\mathrm{N})$ and high $(\mathrm{H})$ value stocks by $30 \%, 40 \%$, and $30 \%$ stocks.

This sorting enables us to get six (06) groups to form six portfolios, SL, SN, SH, BL, $\mathrm{BN}$ and $\mathrm{BH}$ as the intersection of size and book-to-market groups. Likewise, we sort again in the second step for investment from conservative to aggressive stocks forming three groups namely; conservative $(\mathrm{C})$, medium $(\mathrm{N})$ and aggressive $(\mathrm{A})$ investment stocks. It is done by the basis of $30 \%, 40 \%$, and $30 \%$ stocks to yield six portfolios as SC, SN, SA, BC, $\mathrm{BN}$, and BA. Lastly, we sort the size groups again using the same procedure for profitability as robust $(\mathrm{R})$, medium $(\mathrm{N})$ and weak $(\mathrm{W})$ stocks yielding as $\mathrm{SR}, \mathrm{SN}, \mathrm{SW}, \mathrm{BR}, \mathrm{BN}$, and BW.

\footnotetext{
2 The returns of a security are related to the index returns by the market beta. Black, M. C. Jensen, Scholes, and M. C. Jensen (1972), Blume and Friend (1973), and Fama and MacBeth (1973) reduces the errors in the estimated betas of the individual securities by working on portfolio betas. The measurement error often called the endogeneity problem is dealt by building portfolios in a particular way. We address this problem by following Black et al. (1972) and Fama and Mac Beth (1973). They form portfolios and then rank them according to beta size. This study forms portfolios on the same lines. However, it should be remembered that measurement error is a problem of statistical tool while this problem has little or no impact of ANN.

${ }^{3}$ Although the five-factor model could not respond to the Gibbons, Ross, and Shanken (1989) statistical test, it produces good results because the unexplained portion of average returns for individual portfolios are nearly all close to zero. Chiah, Chai, Zhong, and Li (2016) also report improved performance of the five factors model in global equity markets.
} 
The size factor (SMB) is calculated as small size stocks minus big size stocks:

$$
S M B=\frac{(S H+S N+S L)-(B H+B N+B L)}{3} .
$$

The value factor (HML) is calculated as high-value stocks minus low-value stocks:

$$
H M L=\frac{(S H+B H)-(S L+B L)}{2} .
$$

The investment factor (CMA) is calculated as conservative stocks minus aggressive stocks:

$$
C M A=\frac{(S C+B C)-(S C+B A)}{2} .
$$

The profitability factor (RMW) is calculated as robust stocks minus weak stock:

$$
R M W=\frac{(S R+B R)-(S W+B R)}{2} .
$$

The estimated model in this study is Fama and French (2015) 5-Factor (FF5F) given as follow:

$$
R_{P}=R_{f}+\beta_{1}\left(R_{P S X}-R_{f}\right)+\beta_{2}\left(R_{S M B}\right)+\beta_{3}\left(R_{H M L}\right)+\beta_{4}\left(R_{C M A}\right)+\beta_{5}\left(R_{R M W}\right)+\varepsilon_{P} .
$$

We run the model over thirty (30) portfolios sorted from high beta to low beta as a robust procedure adopted by Fama and French (2015). The results are reported for high, mid and low beta portfolios to study the use of ANN for forecasting on different levels of risk.

\subsection{ANN Configuration for asset pricing models}

The parameters of ANN include the training methods and its algorithm and the design of the network. Some studies provide valuable guidelines to develop the neural network design (Masters, 1993; Nelson \& Illingworth, 1991). The instructions suggested by these studies are combined by Kaastra and Boyd (1996) for designing any ANN system for all types of studies. This method is simplified and modified for the present study and the details of the steps are discussed below.

In step 1, the declaration of input and output variables is required. The composite factors of market return, size, value, investment and profitability factors are employed as the inputs while the excess monthly portfolios returns are used as the output (target) of the neural network system. The five-factor model is translated into ANN, and the mathematical representation of the ANN regarding the five factors model is given below:

$$
\begin{aligned}
& R_{P}=G\left(\alpha+\sum_{j=1}^{h} \alpha_{j}\right)+F\left(\beta_{0 j}+\beta_{1 j}\left(R_{P S X}-R_{f}\right)\right)+\beta_{2 j}\left(R_{S M B}\right)+\beta_{3 j}\left(R_{H M L}\right)+ \\
& \beta_{4 j}\left(R_{C M W}\right)+\beta_{5 j}\left(R_{R W A}\right),
\end{aligned}
$$


where $G($.$) is a logistic function (nonlinear function) of the hidden layer, representing the$ transfer function (activation function) and $F($.$) is the activation function of the output layer.$ The processing in the hidden layer cannot be observed due to which this layer is called a hidden layer. The common convention is that the number of hidden layers determine the architecture of the networks (Franses \& Van Dijk, 2000) although some studies consider input layer as a part of NN design (Huang, Yang, \& Chuang, 2008; Pyo, Lee, Cha, \& Jang, 2017; Zhang, Patuwo, \& Hu, 1998).

In step 2, the process of normalization or transformation of the data and distribution of the data among the training, testing, and validation is followed. Data transformation is called preprocessing in the NN system and this process enables the network to learn the fundamental relationships between the input-output variables for better forecasting results. The ANN has its standards of transforming the data depending upon the transfer function in the hidden layer. We use the Sigmoid function and this function requires the data to be normalized between 0 and 1 as mentioned in (Jasic \& Wood, 2004). The prevalent convention of ANN requires the training dataset to be the largest one as compared to the testing and validation dataset (Jasic \& Wood, 2004). The equivalent terms for the in-sample and out sample data in ANN is training and testing, while the validation dataset is an additional step used explicitly by the neural network system to control the asymptotic nature of the neural network model as noted by (Ruxanda \& Badea, 2014). The testing data in the range of $10 \%$ to $30 \%$ is used to evaluate the generalization (out of sample) ability of the system after the training is completed (J.-Z. Wang, J.-J. Wang, Zhang, \& Guo, 2011).

The major challenge of our study is to identify a cost and time effective optimal design of ANN. We take almost all the possible combinations regarding neurons, Data combinations (training, testing, and validation) and portfolio types in terms of the level of risk. We divide the data into a series of combinations to achieve the optimal datasets. The first set is divided into a 60-20-20 combination for training, validation and training set. After this first data set distribution, a five percent variation is allowed to the dataset. Table 1 presents this scheme of data distribution that generates 16 combinations of data sets. The network architecture represents the number of input neurons in the initial layer, hidden layer, and the output layer. The neurons in the input and output layer depend upon the number of input and target variables.

Table 1. Distribution of Dataset (Training, Validation, and Testing)

\begin{tabular}{|c|c|c|c|}
\hline $\begin{array}{c}\text { Dataset } \\
\text { Distribution }\end{array}$ & $\begin{array}{c}\text { Network Architecture } \\
\text { (FF3F Model) }\end{array}$ & $\begin{array}{c}\text { Network Architecture } \\
\text { (FF5F Model) }\end{array}$ & $\begin{array}{c}\text { Hidden Layer } \\
\text { Neurons }\end{array}$ \\
\hline $60-20-20$ & $3-1-1$ to $3-50-1$ & $5-1-1$ to $5-50-1$ & Neuron $1-50$ \\
\hline $65-15-20$ & $3-1-1$ to $3-50-1$ & $5-1-1$ to $5-50-1$ & Neuron $1-50$ \\
\hline $65-20-15$ & $3-1-1$ to $3-50-1$ & $5-1-1$ to $5-50-1$ & Neuron $1-50$ \\
\hline $70-10-20$ & $3-1-1$ to $3-50-1$ & $5-1-1$ to $5-50-1$ & Neuron $1-50$ \\
\hline $70-15-15$ & $3-1-1$ to $3-50-1$ & $5-1-1$ to $5-50-1$ & Neuron $1-50$ \\
\hline $70-20-10$ & $3-1-1$ to $3-50-1$ & $5-1-1$ to $5-50-1$ & Neuron $1-50$ \\
\hline $75-05-20$ & $3-1-1$ to $3-50-1$ & $5-1-1$ to $5-50-1$ & Neuron $1-50$ \\
\hline $75-10-15$ & $3-1-1$ to $3-50-1$ & $5-1-1$ to $5-50-1$ & \\
\hline
\end{tabular}


End of Table 1

\begin{tabular}{|c|c|c|c|}
\hline $\begin{array}{c}\text { Dataset } \\
\text { Distribution }\end{array}$ & $\begin{array}{c}\text { Network Architecture } \\
\text { (FF3F Model) }\end{array}$ & $\begin{array}{c}\text { Network Architecture } \\
\text { (FF5F Model) }\end{array}$ & $\begin{array}{c}\text { Hidden Layer } \\
\text { Neurons }\end{array}$ \\
\hline $75-15-10$ & $3-1-1$ to $3-50-1$ & $5-1-1$ to $5-50-1$ & Neuron $1-50$ \\
\hline $75-20-05$ & $3-1-1$ to $3-50-1$ & $5-1-1$ to $5-50-1$ & Neuron $1-50$ \\
\hline $80-05-15$ & $3-1-1$ to $3-50-1$ & $5-1-1$ to $5-50-1$ & Neuron $1-50$ \\
\hline $80-15-05$ & $3-1-1$ to $3-50-1$ & $5-1-1$ to $5-50-1$ & Neuron $1-50$ \\
\hline $80-10-10$ & $3-1-1$ to $3-50-1$ & $5-1-1$ to $5-50-1$ & Neuron $1-50$ \\
\hline $85-10-05$ & $3-1-1$ to $3-50-1$ & $5-1-1$ to $5-50-1$ & Neuron $1-50$ \\
\hline $85-05-10$ & $3-1-1$ to $3-50-1$ & $5-1-1$ to $5-50-1$ & $5-1-1$ to $5-50-1$ \\
\hline $90-05-10$ & $3-1-1$ to $3-50-1$ & &
\end{tabular}

Step 3 The ANN also describes the transfer function used by the hidden layer (Kaastra \& Boyd, 1996). The term transfer function is used to describe the empirical formula that calculates the outputs of a particular hidden layer or neuron. Other terms used for this process are activation, transformation or squashing functions (Wang et al., 2011). We use the sigmoid the transfer function because of some features which make it more appropriate for a neural network system in financial modeling (Ruxanda \& Badea, 2014). Firstly, due to its nonlinear nature, it can successfully capture the underlying relationship between the input and output variables. Secondly, its differentiation power reduces the error to a minimum level. One of the most commonly used sigmoid function is the logistic function. The resultant curve of this function is "S-shaped" and mathematically it is represented as

$$
S(x)=\frac{1}{1+e^{-x}} .
$$

The detailed network paradigm for this study includes three layers, i.e., an input layer, a hidden layer, and an output layer. The output from the input layer is used by the hidden layer. The maximum limit of neurons in the hidden layer is placed at 50. These neurons work in a series, and the programs compile the best results for each neuron under each combination of the dataset. The output layer consists of a single neuron in the form of the desired target output.

In step 4, the performance of the neural networks is assessed. Many performance evaluation techniques exist to evaluate the neural network system. These measures are used along with a benchmark to compare the performance of the metric itself. We use the Mean Squared Error performance measurement method to avoid some of the pitfalls of other evaluation techniques. This error function may not be the final evaluation criteria, but other standard forecasting evaluation methods, i.e., mean absolute percentage error (MAPE) is typically not minimized in neural networks. The mathematical equation of MSE is given below.

$$
M S E=\frac{1}{N} \sum_{t=1}^{N}\left(R_{t}-\hat{R}_{t}\right)^{2},
$$

where $R_{t}$ and $\hat{R}_{t}$ are, respectively, the actual returns and forecasted returns, and $N$ is the size of the testing dataset. Forecasting errors need to be minimum for forecasting accuracies 
for financial time series. The minimum MSE score is chosen as the best lag point for each network system.

Step 5 requires the selection of a training algorithm. The objective of training is to find the set of optimal weights between the neurons that determine the global minimum of the cost or error function with lower computational power. This set of weights should provide good generalization ability to the out sample data (Ruxanda \& Badea, 2014). The major training functions are Backpropagation function using the Jacobian derivatives and Backpropagation with gradient derivatives. The former function uses the Levenberg-Marquardt and Bayesian Backpropagation algorithm. The latter function uses the Scaled Conjugate Gradient and Quasi-Newton technique etc. We select the Levenberg-Marquardt (LM) method of training the network as most of the stock market research utilizes the backpropagation architecture along the LM method (Burney, Jilani, \& Ardil, 2005).

Furthermore, the LM algorithm is accepted as an alternative to the ordinary least squares method in computational finance. This is the most efficient training method as compared to other techniques, requiring lesser time to minimize the error between actual and predicted values and also need minimum computational power but more storage space (Hagan \& Menhaj, 1994; Tkáč \& Verner, 2016). It is also known as the damped least square equation and is used to solve the nonlinear problems in finance. The method is also considered as the best curve fitting tool in financial analysis and is a robust method of calculating the minimum error in forecasting studies. There are two schools of thought regarding the point at which training should be held. The first stresses the danger of getting trapped in local minima and the difficulty of attaining a global minimum. The second view supports a series of train-test interruptions. Training is stopped after a predetermined number of iterations, the network's ability to generalize on the testing data is evaluated, and training is resumed (Encke, 2008). We use the second approach and set the maximum iterations limit at 1000 .

In step 6, we compile the schemes of instructions for the MATLAB program. The first set of instructions estimates the relationship between the dependent variable (actual or the monthly target returns) and the returns (outputs) produced by the neural network system. This relationship is interpreted as the R-value (regression value) in the ANN setup. If the R-value is substantial, then MSE statistics is much smaller than the mean target variance. This indicates that the neural network has successfully estimated most of the variations in the input-output transformation. An R-value of 1 or $100 \%$ shows a close dependence while an R-value of 0 means poor or random relationship. In the second set of instructions, we run the models over thirty (30) portfolios sorted from high beta to low beta as a robust procedure adopted by (Fama \& French, 2015). The results are reported for high, mid and low beta portfolios to investigate the use of ANN for forecasting the time series of returns on different levels of risk beta. This study predicts the monthly returns at $t+1$ using the data from 1 to $t$ based on the ANN system. The first set of instructions in Matlab calculates the minimum error between the actual and predicted returns of high, medium and low beta portfolios for 16 datasets and 1-50 neurons. This program is based on a simple step ahead reading scheme.

In step 7, we implement the third program based on 48 months rolling window scheme; a widely used technique used in investments analysis and forecasting studies. The purpose of this analysis is to capture any instability in the models and evaluate the forecasting accuracy 
of the system. This strategy is applied to the NN architecture of high, mid, and low beta portfolios. Using this scheme, the program reads the first 48 months observations of all the five input variables; forecasts its portfolio returns at $\mathrm{t}+1$ and compares it with the target portfolio returns. In the second reading, the program rolls forward by one month and $t+2$ is predicted using data from 2 to $t+1$. This process is carried on until the end of the data. The total MSE is calculated for this series. This process is replicated for different nodes and the combinations of training, testing and validation datasets, and MSE statistics is calculated for each combination. The lowest MSE yields the best combination and is used for further testing the model for forecasting.

In step 8, the required MATLAB programs are designed, and the computational power is applied to compile the desired results for analysis.

\section{Results: the correlation between forecasted returns and actual returns}

The regression graph of the five factors model is presented in Figures 1, 2, and 3. These Figures show that the R-value of high and mid beta portfolios is $100 \%$ while low beta portfolios have demonstrated $76 \%$ R-value only. The neural networks have demonstrated its ability to relate the dependent variable (target returns) with the output generated by the independent variables of market returns, size, value, profitability and investment factors. One of the criticisms of the FF5F model is that the HML factor is redundant, but our study finds that the entire composite factors of the FF5F model have contributed significantly to forecast the
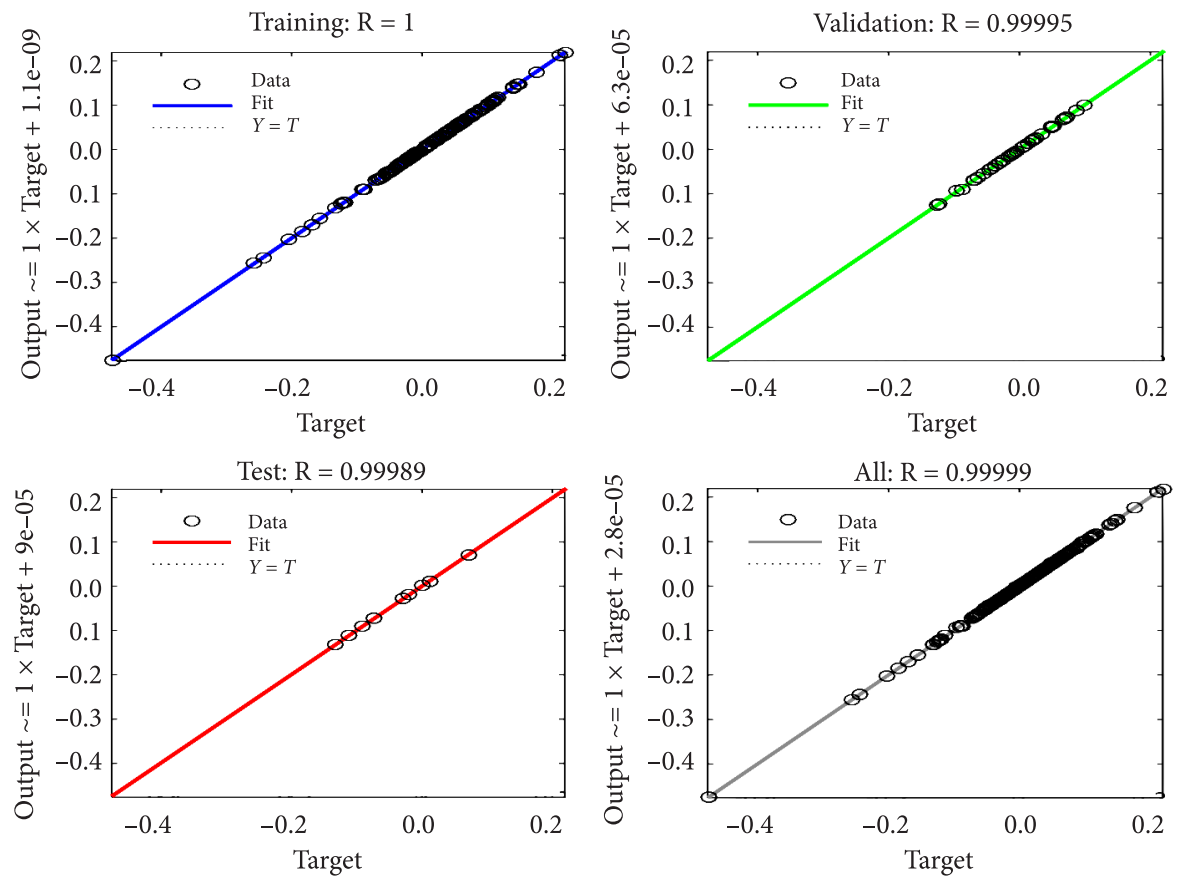

Figure 1. FF5F based Regression Analysis for High Beta Portfolios 

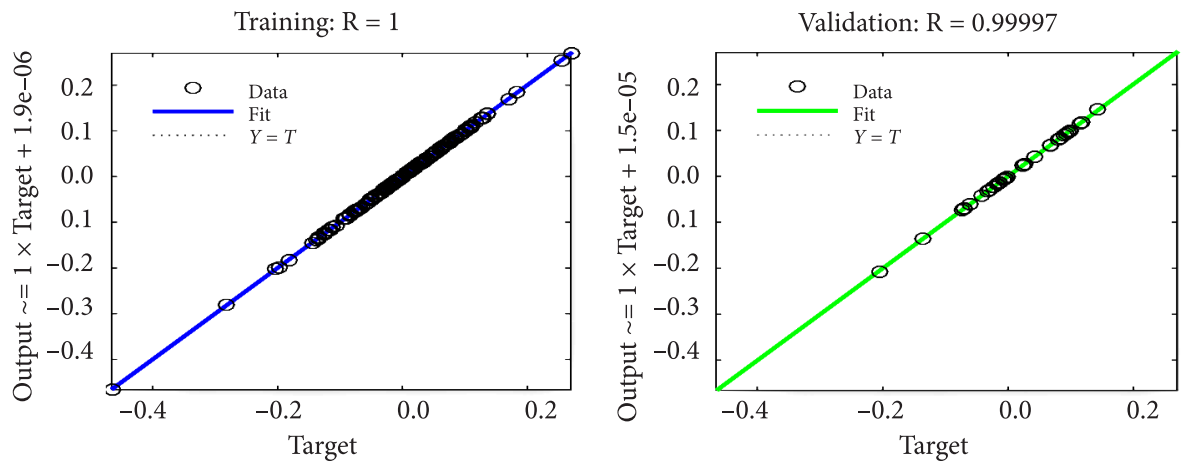

Test: $\mathrm{R}=1$

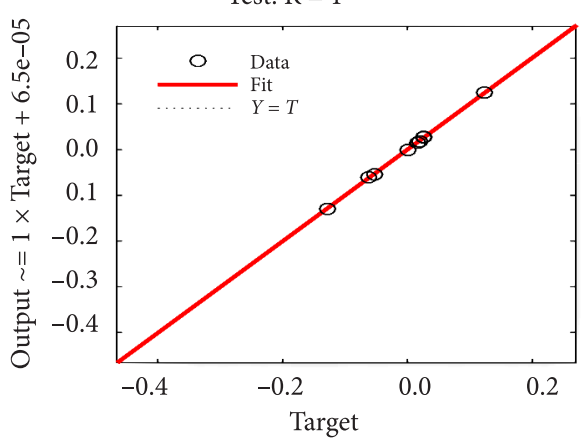

All: $\mathrm{R}=0.99999$

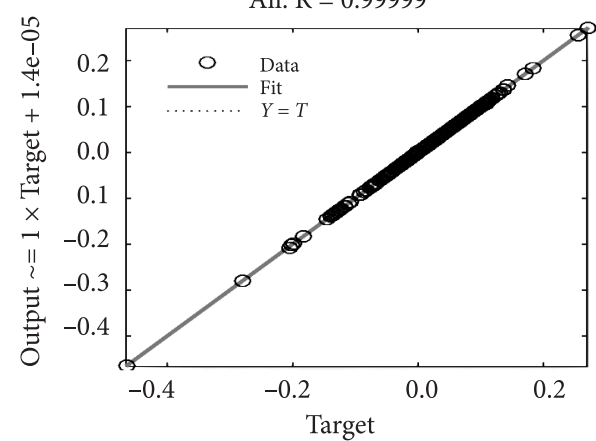

Figure 2. FF5F based Regression Analysis for Mid Beta Portfolios
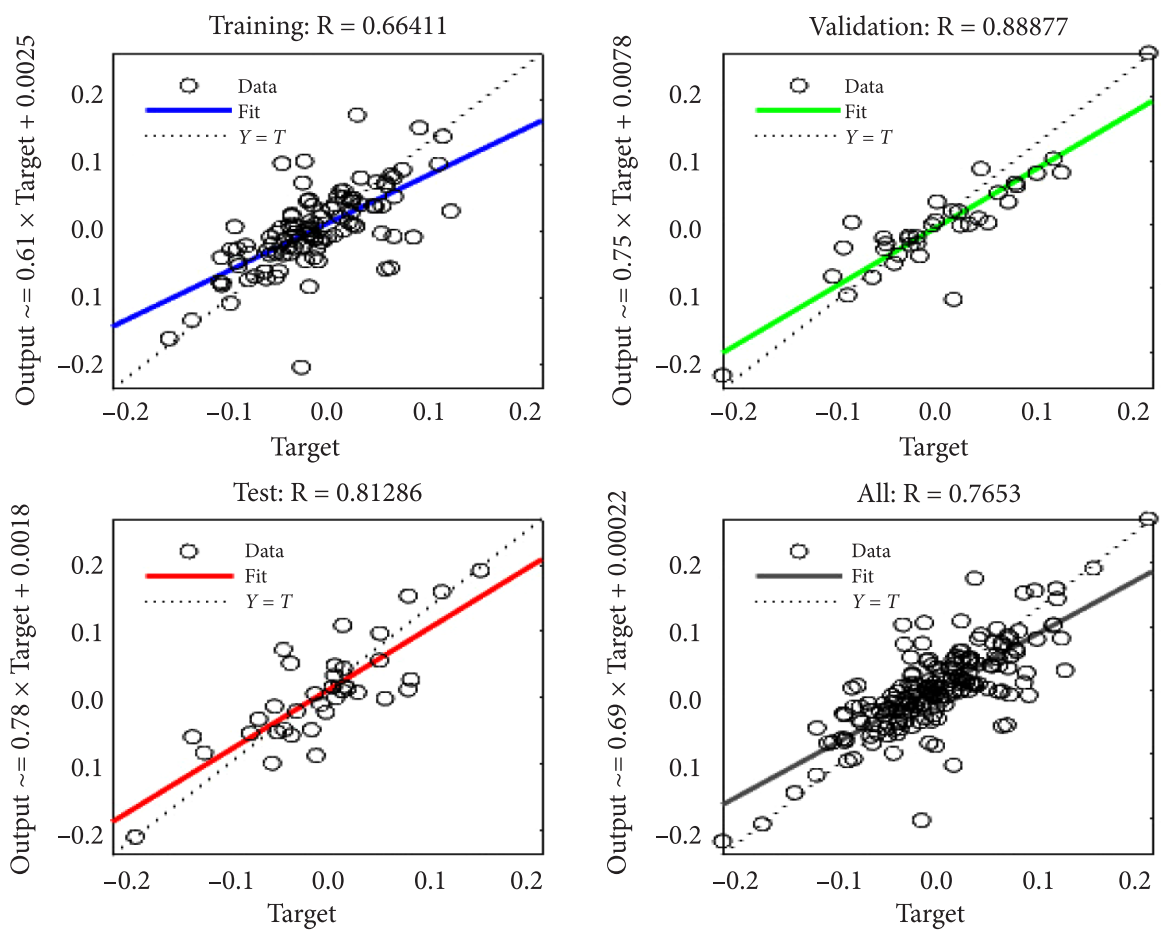

Figure 3. FF5F based Regression Analysis for Low Beta Portfolios 
outputs (monthly returns). One of the postulates of the FF5F model is that the model poorly explains the returns of low beta portfolios. The low beta portfolios have shown only $76 \%$ R-value depicting a poor relationship and this confirms the postulates of the FF5F model.

\subsection{Best ANN model under FF5F model}

In the second scheme of instructions, the neural networks based on equation (6) identified the best ANN design. This system generated 800 networks for a single portfolio by applying the following instructions.

1. The scheme of data distribution, which consisted of 16 Data combinations;

2. The number of hidden layer neurons, which varied from 1 to 50 neurons $(\mathrm{N})$;

3. The application of training algorithms; Levenberg-Marquardt

4. Three input variables five factors model

5. Calculation of error metric between the actual and predicted value of portfolio returns (Mean squared error as an average of training, testing and validation)

A total of 24000 networks were generated for all the 30 portfolios. Each model utilized 180 monthly portfolio returns for the 30 portfolios with one time step. The average MSE statistics of 30 portfolios by the application of 1-50 neurons $(\mathrm{N})$ are presented in Table 2 . The MSE result up to 30 neurons show stability and beyond this threshold level, the system shows instability at intervals. This implies that the use of neurons beyond this level is not appropriate and unnecessary. Table 2 further shows that the results of most of the datasets follow this pattern of hidden layer neurons. The MSE results beyond 30 neurons show that the ANN's loses control beyond the threshold level for these data combinations. This variation of the system seems to be the black box phenomenon of the neural network system beyond the control and understanding of the researcher (Franses \& Van Dijk, 2000).

Table 2 shows the minimum MSE statistics of 0.0035 by the dataset 70-20-05 while the maximum score of 0.0081 is reported by $90-05-05$ dataset up to 30 neurons. The neural network system has placed $98 \%$ of the results in this range. This finding suggests that the five factors model has significant relevant in forecasting the portfolio returns; thus increasing the returns of the investors. The MSE score of all the portfolios and datasets has been plotted in Figure 4. This plotting shows the threshold level of neurons along with all the data combinations and verifies the stable and random performance of our ANN's at different levels hidden layer neurons. Figure 4 depicts the neural network architecture containing the 70-20-05 dataset and 28 neurons, identified as the optimal design for the high, mid, and low beta portfolios. This combination is used for rolling window scheme in section 3.2

Table 2. FF5F based MSE Score of All Portfolios under Various Neurons (N)

\begin{tabular}{|c|c|c|c|c|c|c|c|c|c|c|c|}
\hline Dataset & $\mathrm{N} 1$ & $\mathrm{~N} 2$ & $\mathrm{~N} 3$ & $\mathrm{~N} 4$ & $\mathrm{~N} 5$ & $\mathrm{~N} 10$ & $\mathrm{~N} 20$ & $\mathrm{~N} 28$ & $\mathrm{~N} 30$ & N40 & N50 \\
\hline $60-20-20$ & 0.0070 & 0.0067 & 0.0060 & 0.0058 & 0.0058 & 0.0053 & 0.0053 & 0.0038 & 0.0160 & 0.1587 & 0.0421 \\
\hline $65-15-20$ & 0.0051 & 0.0051 & 0.0052 & 0.0052 & 0.0052 & 0.0053 & 0.0068 & 0.0039 & 0.0161 & 0.0455 & 0.1588 \\
\hline $60-20-15$ & 0.0050 & 0.0051 & 0.0051 & 0.0051 & 0.0051 & 0.0053 & 0.0065 & 0.0038 & 0.0070 & 0.0421 & 0.1587 \\
\hline $70-10-20$ & 0.0052 & 0.0052 & 0.0053 & 0.0054 & 0.0054 & 0.0054 & 0.0069 & 0.0040 & 0.0164 & 0.0455 & 0.1590 \\
\hline
\end{tabular}


End of Table 2

\begin{tabular}{|c|c|c|c|c|c|c|c|c|c|c|c|}
\hline Dataset & $\mathrm{N} 1$ & $\mathrm{~N} 2$ & $\mathrm{~N} 3$ & $\mathrm{~N} 4$ & $\mathrm{~N} 5$ & $\mathrm{~N} 10$ & $\mathrm{~N} 20$ & $\mathrm{~N} 28$ & $\mathrm{~N} 30$ & $\mathrm{~N} 40$ & $\mathrm{~N} 50$ \\
\hline $70-15-15$ & 0.0051 & 0.0051 & 0.0052 & 0.0052 & 0.0053 & 0.0054 & 0.0068 & 0.0038 & 0.0162 & 0.0454 & 0.1588 \\
\hline $70-20-10$ & 0.0050 & 0.0051 & 0.0051 & 0.0051 & 0.0052 & 0.0053 & 0.0068 & 0.0038 & 0.0161 & 0.0422 & 0.1588 \\
\hline $75-05-20$ & 0.0056 & 0.0057 & 0.0057 & 0.0058 & 0.0058 & 0.0059 & 0.0073 & 0.0039 & 0.0203 & 0.0892 & 0.1591 \\
\hline $75-10-15$ & 0.0053 & 0.0053 & 0.0054 & 0.0054 & 0.0054 & 0.0055 & 0.0071 & 0.0039 & 0.0202 & 0.0886 & 0.1590 \\
\hline $75-15-10$ & 0.0052 & 0.0052 & 0.0052 & 0.0053 & 0.0053 & 0.0055 & 0.0071 & 0.0040 & 0.0201 & 0.0454 & 0.0868 \\
\hline $75-20-05$ & 0.0051 & 0.0053 & 0.0053 & 0.0053 & 0.0053 & 0.0053 & 0.0070 & 0.0035 & 0.0200 & 0.0869 & 0.1588 \\
\hline $80-05-15$ & 0.0058 & 0.0059 & 0.0060 & 0.0060 & 0.0060 & 0.0062 & 0.0074 & 0.0040 & 0.0204 & 0.0894 & 0.1596 \\
\hline $80-10-10$ & 0.0053 & 0.0053 & 0.0055 & 0.0055 & 0.0055 & 0.0057 & 0.0071 & 0.0041 & 0.0202 & 0.0888 & 0.1590 \\
\hline $80-15-05$ & 0.0052 & 0.0052 & 0.0052 & 0.0053 & 0.0053 & 0.0055 & 0.0071 & 0.0046 & 0.0201 & 0.0869 & 0.1589 \\
\hline $85-05-10$ & 0.0061 & 0.0062 & 0.0063 & 0.0063 & 0.0063 & 0.0065 & 0.0074 & 0.0052 & 0.0220 & 0.0927 & 0.1609 \\
\hline $85-10-05$ & 0.0053 & 0.0055 & 0.0055 & 0.0056 & 0.0056 & 0.0057 & 0.0068 & 0.0042 & 0.0165 & 0.0541 & 0.1591 \\
\hline $90-05-05$ & 0.0067 & 0.0068 & 0.0068 & 0.0070 & 0.0071 & 0.0072 & 0.0081 & 0.0076 & 0.0180 & 0.0582 & 0.1650 \\
\hline
\end{tabular}

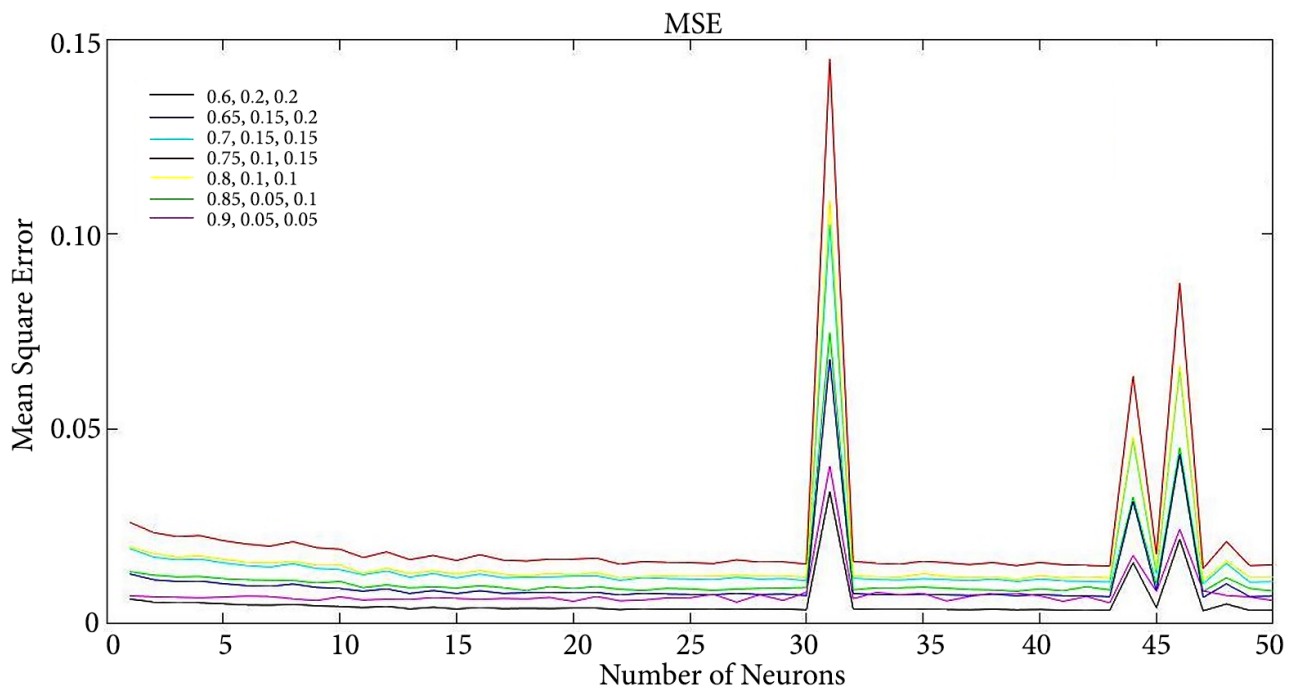

Figure 4. MSE Results of all datasets under ANN using FF5C model

\subsection{Rolling window results for high, mid and low beta portfolios using ANN configuration}

In this section, we further evaluate and analyze the optimal ANN designs (Datasets and Neurons) identified in section 3.1, by using rolling window strategy with an estimation window of 48 months and rolled forward on a monthly basis. We get 133 networks for each portfolio and 133 forecasting results for each architecture. A total of 3990 monthly predictions are generated and these returns are annualized and reported as high, mid, and low beta returns 
for the better understanding of the users. Table 3 exhibits the actual and predicted returns for the three classes of portfolios for 11 years. It is pertinent to mention here that the time taken by the rolling windows program to compile the errors is huge as compared to the previous simple one step ahead scheme.

Table 3 shows that the minimum and maximum annualized predicted returns of the high, mid and low beta portfolios are $-55.34 \%-29.30 \%,-52.85 \%-54.73 \%$, and $-49.72 \%-54.37 \%$ respectively for 11 consecutive years. The range of actual returns for the same data period is $-55.44 \%$ to $30.09 \%,-51.85 \%$ to $55.68 \%$ and $-49.03 \%$ to $55.52 \%$. The analysis of Table 3 demonstrates that the predicted returns are closely following the actual returns for most of the years. Our ANN system has captured the pattern of the monthly returns accurately and exhibits its capability to identify the positive and negative direction of the market as well with some exceptions. The analysis of the actual portfolio returns of the market depicts important dynamics of this emerging market. The economy was passing through positive structural reforms and the capital markets were experiencing a continuous flow of foreign investments in the years 2004 to 2006 . The stock market index was gaining due to the increased portfolio investments by foreign investors.

Table 3. FF5F based Actual Vs. Predicted (Annualized) Returns with MSE

\begin{tabular}{|c|c|c|c|c|c|c|c|c|c|}
\hline & \multicolumn{2}{|c|}{ High Beta Portfolios } & \multicolumn{3}{c|}{ Mid Beta Portfolios } & \multicolumn{3}{c|}{ Low Beta Portfolios } \\
\hline Year & $\begin{array}{c}\text { Actual } \\
\text { Returns } \\
\%\end{array}$ & $\begin{array}{c}\text { Predic- } \\
\text { ted Re- } \\
\text { turns } \%\end{array}$ & MSE & $\begin{array}{c}\text { Actual } \\
\text { Returns } \\
\%\end{array}$ & $\begin{array}{c}\text { Predict- } \\
\text { ed Re- } \\
\text { turns\% }\end{array}$ & MSE & $\begin{array}{c}\text { Actual } \\
\text { Returns } \\
\%\end{array}$ & $\begin{array}{c}\text { Predic- } \\
\text { ted Re- } \\
\text { turns \% }\end{array}$ & MSE \\
\hline 2004 & 30.09 & 29.30 & 0.0079 & 32.26 & 31.26 & .01000 & 55.52 & 54.37 & 0.0115 \\
\hline 2005 & 22.93 & 22.20 & 0.0073 & 22.24 & 21.55 & 0.0069 & 23.75 & 22.57 & 0.0118 \\
\hline 2006 & -1.90 & -2.48 & 0.0058 & -14.20 & -14.73 & 0.0053 & -18.05 & -18.60 & 0.0055 \\
\hline 2007 & 16.83 & 16.08 & 0.0075 & 29.95 & 29.45 & 0.0050 & 41.37 & 40.66 & 0.0071 \\
\hline 2009 & -54.44 & -55.34 & 0.0090 & -51.85 & -52.85 & 0.011 & -49.03 & -49.72 & 0.0068 \\
\hline 2010 & -15.95 & -17.44 & 0.0149 & -25.04 & -26.18 & 0.0114 & -28.37 & -29.47 & 0.0109 \\
\hline 2011 & -19.19 & -22.84 & 0.0365 & -15.67 & -16.55 & 0.0088 & -22.17 & -23.37 & 0.0120 \\
\hline 2012 & -11.00 & -12.34 & 0.1 .34 & -35.03 & -36.66 & 0.0163 & -25.45 & -26.41 & 0.0097 \\
\hline 2013 & 12.03 & 11.14 & 0.0089 & 55.68 & 54.73 & 0.0095 & 70.56 & 69.41 & 0.0115 \\
\hline 2014 & 20.35 & 19.92 & 0.0042 & 15.29 & 14.85 & 0.0044 & 12.09 & 11.54 & 0.0055 \\
\hline 2015 & 21.04 & 20.58 & 0.0046 & 40.56 & 40.12 & 0.0044 & 30.53 & 29.45 & 0.0108 \\
\hline Average & 1.89 & 0.80 & 0.0109 & 4.93 & 4.09 & 0.0084 & 8.25 & 7.31 & 0.0094 \\
\hline
\end{tabular}

This growth period was followed by the most turbulent years; marked with political instability, negative trade balance, turmoil in international financial markets and internal law and order situation. The returns of the years 7 to 12 exhibits the impact of these events and show suppressed and negative behavior. The system has successfully predicted the negative and positive direction of the market in various years. This is a significant finding and concludes that the proposed method of artificial neural network predicts the direction of a volatile 
market accurately along with a close picture of returns. This finding can be practically applied by floor traders in Pakistan Equity market to beat the market and earn excess returns for the investors. The analysis of Table 3 further shows that the predictive ability of the networks on selected high and mid beta portfolios is closely matching the market in most of the intervals as compared to low beta portfolios while the low beta portfolios demonstrate wide variation in predictive returns. We find that the investors have low chances of accurate prediction of returns in the low-risk stocks and portfolios.

The MSE statistics reported in Table 3 for each year and each class of the portfolios is plotted against time and presented in Figure 5. The error for the mid and low beta portfolios is consistently minimizing for the first seven years of the sample period and show variations in the year 2012 and 2013. The high beta portfolios are showing wide variation in the years 2010 to 2012. This variation is a close depiction of the actual index movement in the corresponding years.

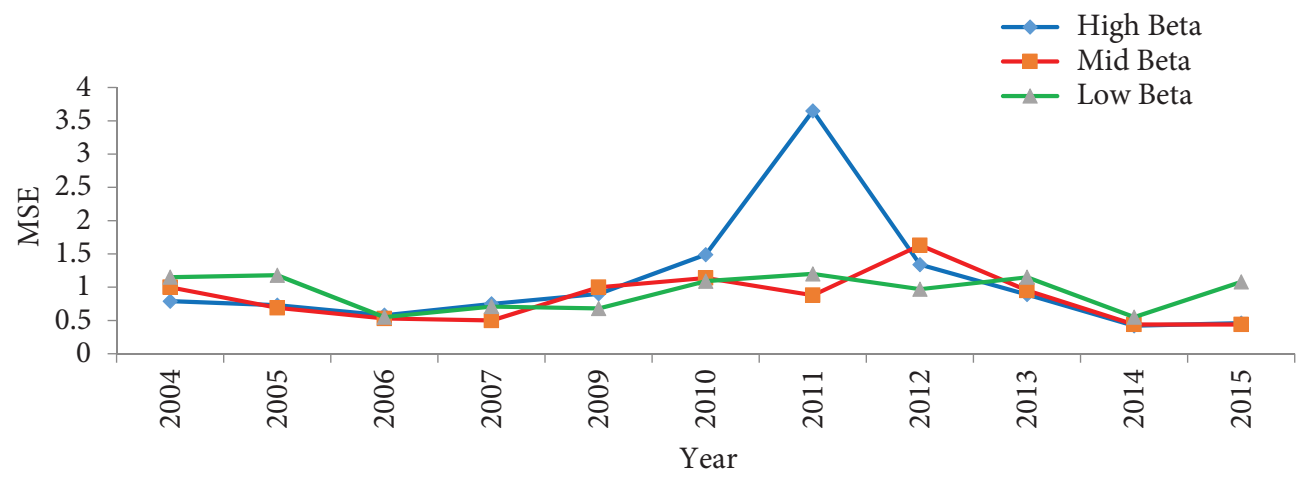

Figure 5. MSE score of high, mid and low portfolios under rolling windows scheme

Figure 5 exhibits another significant finding related to the training time of the networks. The training curve has shown wide variations even at the end of the training in case of all the three portfolios. This finding validates the concept of the neural network as noted by Stansell and Eakins (2004) that the addition of more variables, although refines the forecasting performance of the system, the learning time also increases. The t-statistics of the high, mid, and low beta portfolios are $0.143,0.281$, and 0.656 respectively. It means that all the three null hypothesis are accepted, and there is no statistical difference between predicted and actual returns.

\subsection{In-sample and out sample analysis of FF5F based results}

The in-sample and out sample theory in the data analysis suggest that the predicted value on both samples should demonstrate a consistent picture of returns. Under this scheme, the program segregates the resultant error among the training (in sample), Testing (out sample) and validation (controlling) for the three classes of portfolios. Table 4 presents this MSE score in segregated form. 
Table 4. In-Sample and Out-Sample MSE Statistics of FF5F Model

\begin{tabular}{|l|c|c|c|}
\hline \multirow{2}{*}{ Portfolios Type } & \multicolumn{2}{|c|}{ In-Sample } & Out-Sample \\
\cline { 2 - 4 } & Training & Validation & Testing \\
\hline High Beta & 0.0023 & 0.0045 & 0.0012 \\
\hline Mid Beta & 0.0029 & 0.0086 & 0.0058 \\
\hline Low Beta & 0.0030 & 0.0083 & 0.0021 \\
\hline
\end{tabular}

A systematic minimization of error takes place among the three states of the neural networks. The lowest score of MSE for high beta portfolios on in-sample (overlapping training) and out sample dataset and validation sets are $0.0023,0.0045$, and 0.0012 . The uniformity of error for the three classes of portfolios shows that the error is gradually decreasing on training, validation and testing datasets. The ANN has successfully generalized the relationships and validates the conceptual foundation of the artificial neural networks evidenced by (Donaldson \& Kamstra, 1997) that the successful application of ANN on long and noisy data should return a systematic minimization of errors on in sample and out sample data. This finding is promising for the investors because they can employ our proposed system to predict one month ahead returns. The stakeholders can modify their investment strategies by using our proposed ANN methodology successfully in stock markets.

\section{Discussion of the results}

This paper investigates the predictive ability of the Artificial Neural Networks in Pakistan's Equity market by using the composite factors of Fama and French five factors model. The primary aim is to identify the ANN design that provides the best description of future returns. ANN conducts the principal measure and a total of thirty portfolios are constructed, categorized as high, mid and low beta portfolios. The initial testing of ANN is conducted through wide experimentation, while a rolling scheme is applied to the portfolio returns to establish the stability and resilience of the proposed ANN models. We conducted wide experimentation with datasets and the number of neurons on the Fama and French five factors models to evaluate the simulated returns of the portfolios. These experiments reveal that the composite style factors can accurately predict one period ahead stock returns and closely follow the negative and positive direction of the market.

The initial testing of the model has converged the best results at 75-20-05 dataset with 28 neurons and the success rate of accurate prediction of all the time intervals is $98 \%$. The regression analysis and goodness of fit test have also shown closer results. The annualized predicted returns of the high, mid and low beta portfolios demonstrate a minimum error with the actual returns for 11 consecutive years. The low beta portfolios, however, show wide variation in predicting portfolio returns, implying that the low beta portfolios have low chances of accurate prediction by the neural networks. A systematic minimization of error is reported among the three states of the neural networks verifying the conceptual foundation of the ANN. The performance of the system on the out sample data is also promising because most of the other techniques demonstrate a good in sample performance but poor out sample ability. 


\section{Conclusions}

Many fields including stock markets have recognized the forecasting capability of artificial neural networks. The pattern recognition and learning abilities of the artificial neural network in a data-rich environment of stock markets present a valuable opportunity for the investor. The investors have the opportunity to modify their buy and hold strategy and adopt an active behavior in investments. The Neural network models based on the five composite factors of FF5F model opens new vistas for investors to organize their investment portfolios more efficiently and earn excess returns. Although the portfolios based on Fama \& French methodology using ANN models have accurately predicted the returns, it remains open to more experimentation. At this point, given the "black box" nature of the ANN, it is the major limitation for ANN to offer any explanation beyond its well-known ability to capture "hidden" relationships between inputs and outputs.

Future researchers with finance background should focus on the use of ANN.s strengths in Clustering and classification in the Portfolio formation and the Application of Particle swarm optimization in the construction of portfolios based on betas. A comparative analysis of our results with conventional forecasting techniques will determine the robustness of the two methods. Similarly, the application of Cross-validation method for data distribution can assign more scientific foundation to the datasets for ANN. The application of regression neural networks to the theory of asset pricing is another important area which can be investigated in future research. Finally, the established conceptual foundation of the asset pricing models on the linear risk returns relationship also needs to be revisited by using artificial intelligence techniques. The future research in the fields of both asset pricing and artificial intelligence would be able to offer an opportunity for interdisciplinary research and present more challenges to the established asset pricing models.

\section{Acknowledgements}

The Authors are grateful to the valuable inputs of Mr. Nahmanul Haq and Dr. Asim Afridi in the designing of Software and Tables. We are also thankful to the valuable comments of the Journal's Editor and the Reviewers whose inputs assigned significant positioning to our research work.

\section{Funding}

This study is the result of a PhD Thesis, Organized and financed by the Authors and no Funding Agency is involved in this research.

\section{Author contributions}

Dr. Usman Ayub initiated the idea of applying the ANN system to the theory of asset pricing, supervised the research, and provided the data from the DataStream. Muhammad Naveed Jan designed the methodology, conducted the experiments and designed the MATLAB 
software, organized and analyzed the results, designed the figures, Tables and organized the References and formatted the paper according to the journal's format.

\section{Disclosure statement}

The authors declare no conflict of interest or other competing interests from any other party.

\section{References}

Ahmad, H., \& Javid, A. (2009). Dynamics and determinants of dividend policy in Pakistan: Evidence from Karachi stock exchange non-financial listed firms. International Research Journal of Finance and Economics, 25, 148-171.

Armano, G., Marchesi, M., \& Murru, A. (2005). A hybrid genetic-neural architecture for stock indexes forecasting. Information Sciences, 170(1), 3-33. https://doi.org/10.1016/j.ins.2003.03.023

Ayub, U., Shah, S. Z. A., \& Abbas, Q. (2015). Robust analysis for downside risk in portfolio management for a volatile stock market. Economic Modelling, 44, 86-96.

https://doi.org/10.1016/j.econmod.2014.10.001

Bekaert, G., Harvey, C. R., \& Lundblad, C. (2005). Does financial liberalization spur growth? Journal of Financial Economics, 77(1), 3-55. https://doi.org/10.1016/j.jfineco.2004.05.007

Black, F., Jensen, M. C., Scholes, M., \& Jensen, M. C. (1972). Studies in the Theory of Capital Markets. The Capital Asset Pricing Model: Some Empirical Tests.

Blume, M. E., \& Friend, I. (1973). A new look at the capital asset pricing model. The Journal of Finance, 28(1), 19-34. https://doi.org/10.1111/j.1540-6261.1973.tb01342.x

Bonfiglioli, A. (2008). Financial integration, productivity and capital accumulation. Journal of International Economics, 76(2), 337-355. https://doi.org/10.1016/j.jinteco.2008.08.001

Burney, S. M. A., Jilani, T. A., \& Ardil, C. (2005). Levenberg-Marquardt algorithm for Karachi Stock Exchange share rates forecasting. International Journal of Computational Intelligence, 1(3), 144-149.

Cao, Q., Leggio, K. B., \& Schniederjans, M. J. (2005). A comparison between Fama and French's model and artificial neural networks in predicting the Chinese stock market. Computers \& Operations Research, 32(10), 2499-2512. https://doi.org/10.1016/j.cor.2004.03.015

Cao, Q., Parry, M. E., \& Leggio, K. B. (2011). The three-factor model and artificial neural networks: predicting stock price movement in China. Annals of Operations Research, 185(1), 25-44. https://doi.org/10.1007/s10479-009-0618-0

Carvalhal, A., \& Ribeiro, T. (2008). Do artificial neural networks provide better forecasts? Evidence from Latin American stock indexes. Latin American Business Review, 8(3), 92-110. https://doi.org/10.1080/10978520802035463

Catik, A. N., \& Karaçuka, M. (2012). A comparative analysis of alternative univariate time series models in forecasting Turkish inflation. Journal of Business Economics and Management, 13(2), 275-293. https://doi.org/10.3846/16111699.2011.620135

Chan, K. S., \& Tong, H. (1986). On estimating thresholds in autoregressive models. Journal of Time Series Analysis, 7(3), 179-190. https://doi.org/10.1111/j.1467-9892.1986.tb00501.x

Chiah, M., Chai, D., Zhong, A., \& Li, S. (2016). A better model? An empirical investigation of the Fama-French five-factor model in Australia. International Review of Finance, 16(4), 595-638. https://doi.org/10.1111/irfi.12099

Danial, S. N., Noor, S. R., Usmani, B. A., \& Zaidi, S. J. H. (2008). A dynamical system and neural network perspective of Karachi stock exchange. In International Multi Topic Conference (pp. 88-99). Springer. https://doi.org/10.1007/978-3-540-89853-5_11 
Dixit, G., \& Roy, D. (2013). Predicting India Volatility Index: An Application of Artificial Neural Network. International Journal of Computer Applications, 70(4), 22-30. https://doi.org/10.5120/11950-7768

Donaldson, R. G., \& Kamstra, M. (1997). An artificial neural network-GARCH model for international stock return volatility. Journal of Empirical Finance, 4(1), 17-46. https://doi.org/10.1016/S0927-5398(96)00011-4

Encke, D. (2008). Neural network-based stock market return forecasting using data mining for variable reduction. In Data Warehousing and Mining: Concepts, Methodologies, Tools, and Applications (pp. 2476-2493). IGI Global. https://doi.org/10.4018/978-1-59904-951-9.ch151

Fadlalla, A., \& Amani, F. (2014). Predicting next trading day closing price of Qatar exchange index using technical indicators and artificial neural networks. Intelligent Systems in Accounting, Finance and Management, 21(4), 209-223. https://doi.org/10.1002/isaf.1358

Fama, E. F., \& French, K. R. (2015). A five-factor asset pricing model. Journal of Financial Economics, 116(1), 1-22. https://doi.org/10.1016/j.jfineco.2014.10.010

Fama, E. F., \& MacBeth, J. D. (1973). Risk, return, and equilibrium: Empirical tests. Journal of Political Economy, 81(3), 607-636. https://doi.org/10.1086/260061

Fatima, S., \& Hussain, G. (2008). Statistical models of KSE100 index using hybrid financial systems. Neurocomputing, 71(13-15), 2742-2746. https://doi.org/10.1016/j.neucom.2007.11.044

Fescioglu-Unver, N., \& Tanyeri, B. (2013). A comparison of artificial neural network and multinomial logit models in predicting mergers. Journal of Applied Statistics, 40(4), 712-720. https://doi.org/10.1080/02664763.2012.750717

Franses, P. H., \& Van Dijk, D. (2000). Non-linear time series models in empirical finance. Cambridge University Press. https://doi.org/10.1017/CBO9780511754067

Ghufran, B., Awan, H. M., Khakwani, A. K., \& Qureshi, M. A. (2016). What causes stock market volatility in Pakistan? Evidence from the field. Economics Research International, 2016. https://doi.org/10.1155/2016/3698297

Gibbons, M. R., Ross, S. A., \& Shanken, J. (1989). A test of the efficiency of a given portfolio. Econometrica: Journal of the Econometric Society, 1121-1152. https://doi.org/10.2307/1913625

Gokgoz, F., \& Sezgin-Alp, O. (2014). Estimating the Turkish sectoral market returns via arbitrage pricing model under neural network approach. International Journal of Economics and Finance, 7(1), 154. https://doi.org/10.5539/ijef.v7n1p154

Gonzalez Miranda, F., \& Burgess, N. (1997). Modelling market volatilities: the neural network perspective. The European Journal of Finance, 3(2), 137-157. https://doi.org/10.1080/135184797337499

Gray, A., Steinfort, R., \& McIntosh, R. (2012). Myths and misconceptions about indexing. Retrieved from https://static.vgcontent.info/crp/intl/auw/docs/literature/Myths-Misconceptions-About-Indexing. pdf?20181009|121330

Guan, H., Dai, Z., Zhao, A., \& He, J. (2018). A novel stock forecasting model based on High-orderfuzzy-fluctuation trends and back propagation neural network. PloS One, 13(2). https://doi.org/10.1371/journal.pone.0192366

Guotai, C., Abedin, M. Z., \& Moula, F.-E. (2017). Modeling credit approval data with neural networks: an experimental investigation and optimization. Journal of Business Economics and Management, 18(2), 224-240. https://doi.org/10.3846/16111699.2017.1280844

Hagan, M. T., \& Menhaj, M. B. (1994). Training feedforward networks with the Marquardt algorithm. IEEE Transactions on Neural Networks, 5(6), 989-993. https://doi.org/10.1109/72.329697

Haider, S., \& Nishat, M. (2009). On testing efficiency of Karachi Stock Exchange using computational intelligence. In Information and Financial Engineering, 2009. ICIFE 2009. International Conference on (pp. 32-36). IEEE. https://doi.org/10.1109/ICIFE.2009.31 
Hossain, A., \& Nasser, M. (2011). Comparison of the finite mixture of ARMA-GARCH, back propagation neural networks and support-vector machines in forecasting financial returns. Journal of Applied Statistics, 38(3), 533-551. https://doi.org/10.1080/02664760903521435

Huang, C.-J., Yang, D.-X., \& Chuang, Y.-T. (2008). Application of wrapper approach and composite classifier to the stock trend prediction. Expert Systems with Applications, 34(4), 2870-2878. https://doi.org/10.1016/j.eswa.2007.05.035

Iqbal, Z. (2013). Efficient machine learning techniques for stock price prediction. International Journal of Engineering Research and Applications, 3(6), 855-867.

Jabbari, E., \& Fathi, Z. (2014). Prediction of stock returns using financial ratios based on historical cost, compared with adjusted prices (accounting for inflation) with neural network approach. Indian Journal of Fundamental and Applied Life Sciences 4(4), 1064-1078.

Jasic, T., \& Wood, D. (2004). The profitability of daily stock market indices trades based on neural network predictions: Case study for the S\&P 500, the DAX, the TOPIX and the FTSE in the period 19651999. Applied Financial Economics, 14(4), 285-297. https://doi.org/10.1080/0960310042000201228

Kaastra, I., \& Boyd, M. (1996). Designing a neural network for forecasting financial and economic time series. Neurocomputing, 10(3), 215-236. https://doi.org/10.1016/0925-2312(95)00039-9

Kamruzzaman, J. (2006). Artificial neural networks in finance and manufacturing. IGI Global. https://doi.org/10.4018/978-1-59140-670-9

Kanas, A., \& Yannopoulos, A. (2001). Comparing linear and nonlinear forecasts for stock returns. International Review of Economics \& Finance, 10(4), 383-398. https://doi.org/10.1016/S1059-0560(01)00092-2

Karaban, S., \& Maguire, G. (2012). S\&P Indices Versus Active Funds Scorecard (SPIVA Australia Scorecard). S\&P Dow Jones Indices. Australia: S\&P Dow Jones Indices LLC.

Kim, N., \& Mangi, F. (2016). What's next for Asia's best-performing stock market. Bloomberg Markets. Retrieved from https://Www. Bloomberg. Com Google Scholar.

Ko, P.-C., \& Lin, P.-C. (2008). Resource allocation neural network in portfolio selection. Expert Systems with Applications, 35(1-2), 330-337. https://doi.org/10.1016/j.eswa.2007.07.031

Lendasse, A., de Bodt, E., Wertz, V., \& Verleysen, M. (2000). Non-linear financial time series forecasting-Application to the Bel 20 stock market index. European Journal of Economic and Social Systems, 14(1), 81-91. https://doi.org/10.1051/ejess:2000110

Levine, R. (2008). Finance and the Poor. The Manchester School, 76, 1-13. https://doi.org/10.1111/j.1467-9957.2008.01078.x

Liang, H., Yang, C., \& Cai, C. (2017). Beauty contest, bounded rationality, and sentiment pricing dynamics. Economic Modelling, 60, 71-80. https://doi.org/10.1016/j.econmod.2016.09.010

Majhi, R., Panda, G., \& Sahoo, G. (2009). Development and performance evaluation of FLANN based model for forecasting of stock markets. Expert Systems with Applications, 36(3), 6800-6808. https://doi.org/10.1016/j.eswa.2008.08.008

Maknickienė, N., \& Maknickas, A. (2013a). Financial market prediction system with Evolino neural network and Delphi method. Journal of Business Economics and Management, 14(2), 403-413. https://doi.org/10.3846/16111699.2012.729532

Maknickienė, N., \& Maknickas, A. (2013b). Financial market prediction system with Evolino neural network and Delphi method. Journal of Business Economics and Management, 14(2), 403-413. https://doi.org/10.3846/16111699.2012.729532

Malkiel, B. G. (2011). The efficient-market hypothesis and the financial crisis. In Rethinking finance: perspectives on the crisis (Proceedings of a conference). Russel Sage Foundation.

Masters, T. (1993). Practical Neural Network Recipies in C++. 24Morgan Kaufmann. 
McMillan, D. G. (2003). Non-linear predictability of UK stock market returns. Oxford Bulletin of Economics and Statistics, 65(5), 557-573. https://doi.org/10.1111/j.1468-0084.2003.00061.x

McNelis, P. D. (2005). Neural networks in finance: gaining predictive edge in the market. Academic Press.

Moghaddam, A. H., Moghaddam, M. H., \& Esfandyari, M. (2016). Predicción del índice del mercado bursátil utilizando una red neuronal artificial. Journal of Economics, Finance and Administrative Science, 21(41), 89-93. https://doi.org/10.1016/j.jefas.2016.07.002

Munir, S., Chaudhry, I. S., \& Akhtar, M. H. (2013). Financial Liberalization and Economic Growth in Pakistan: Empirical Evidence from Co-integration Analysis. Pakistan Journal of Social Sciences (PJSS), 33(2).

Nelson, M. M., \& Illingworth, W. T. (1991). A practical guide to neural nets (July 1, 1991). United States: Prentice Hall PTR; Har/Dskt.

O'Connor, N., \& Madden, M. G. (2006). A neural network approach to predicting stock exchange movements using external factors. In Applications and Innovations in Intelligent Systems XIII (pp. 64-77). Springer. https://doi.org/10.1007/1-84628-224-1_6

Olson, D., \& Mossman, C. (2003). Neural network forecasts of Canadian stock returns using accounting ratios. International Journal of Forecasting, 19(3), 453-465. https://doi.org/10.1016/S0169-2070(02)00058-4

Oztekin, A., Kizilaslan, R., Freund, S., \& Iseri, A. (2016). A data analytic approach to forecasting daily stock returns in an emerging market. European Journal of Operational Research, 253(3), 697-710. https://doi.org/10.1016/j.ejor.2016.02.056

Pyo, S., Lee, J., Cha, M., \& Jang, H. (2017). Predictability of machine learning techniques to forecast the trends of market index prices: Hypothesis testing for the Korean stock markets. PloS One, 12(11). https://doi.org/10.1371/journal.pone.0188107

Qiu, M., \& Song, Y. (2016). Predicting the direction of stock market index movement using an optimized artificial neural network model. PloS One, 11(5). https://doi.org/10.1371/journal.pone.0155133

Quah, T.-S. (2008). DJIA stock selection assisted by neural network. Expert Systems with Applications, 35(1-2), 50-58. https://doi.org/10.1016/j.eswa.2007.06.039

Racicot, F.-E., \& Rentz, W. F. (2016). Testing Fama-French's new five-factor asset pricing model: evidence from robust instruments. Applied Economics Letters, 23(6), 444-448.

Rechenthin, M. D. (2014). Machine-learning classification techniques for the analysis and prediction of high-frequency stock direction (Doctoral dissertation). The University of Iowa.

Rojas, R. (2013). Neural networks: a systematic introduction. Springer Science \& Business Media.

Ruxanda, G., \& Badea, L. M. (2014). Configuring artificial neural networks for stock market predictions. Technological and Economic Development of Economy, 20(1), 116-132. https://doi.org/10.3846/20294913.2014.889051

Sargent, T. J. (1993). Bounded rationality in macroeconomics: The Arne Ryde memorial lectures. OUP Catalogue.

Sgroi, D., \& Zizzo, D. J. (2007). Neural networks and bounded rationality. Physica A: Statistical Mechanics and Its Applications, 375(2), 717-725. https://doi.org/10.1016/j.physa.2006.10.026

Sonsino, D., \& Shavit, T. (2014). Return prediction and stock selection from unidentified historical data. Quantitative Finance, 14(4), 641-655. https://doi.org/10.1080/14697688.2012.712210

Stansell, S. R., \& Eakins, S. G. (2004). Forecasting the direction of change in sector stock indexes: An application of neural networks. Journal of Asset Management, 5(1), 37-48. https://doi.org/10.1057/palgrave.jam.2240126

State Bank of Pakistan. (2015). Financial Stability Review (SBP Annual Publication No. 2015) (pp. 109111). Pakistan. Retrieved from http://www.sbp.org.pk/FSR/2015/pdf/Chapter-07.pdf 
Staub, S., Karaman, E., Kaya, S., Karapınar, H., \& Güven, E. (2015). Artificial neural network and agility. Procedia-Social and Behavioral Sciences, 195, 1477-1485. https://doi.org/10.1016/j.sbspro.2015.06.448

Tkáč, M., \& Verner, R. (2016). Artificial neural networks in business: two decades of research. Applied Soft Computing, 38, 788-804. https://doi.org/10.1016/j.asoc.2015.09.040

Tong, H. (1978). On a threshold model. In Pattern Recognition and Signal Processing (pp. 575-586). Sijthoff \& Noordhoff, Netherlands. https://doi.org/10.1007/978-94-009-9941-1_24

Tong, H., \& Lim, K. S. (1980). Threshold autoregression, limit cycles and cyclical data. Journal of the Royal Statistical Society. Series B (Methodological), 245-292. https://doi.org/10.1111/j.2517-6161.1980.tb01126.x

Vortelinos, D. I. (2017). Forecasting realized volatility: HAR against Principal Components Combining, neural networks and GARCH. Research in International Business and Finance, 39, 824-839. https://doi.org/10.1016/j.ribaf.2015.01.004

Walczak, S. (2001). An empirical analysis of data requirements for financial forecasting with neural networks. Journal of Management Information Systems, 17(4), 203-222. https://doi.org/10.1080/07421222.2001.11045659

Wang, J.-Z., Wang, J.-J., Zhang, Z.-G., \& Guo, S.-P. (2011). Forecasting stock indices with back propagation neural network. Expert Systems with Applications, 38(11), 14346-14355. https://doi.org/10.1016/j.eswa.2011.04.222

Wang, L., Wang, Z., Zhao, S., \& Tan, S. (2015). Stock market trend prediction using dynamical Bayesian factor graph. Expert Systems with Applications, 42(15-16), 6267-6275. https://doi.org/10.1016/j.eswa.2015.01.035

Zahedi, J., \& Rounaghi, M. M. (2015). Application of artificial neural network models and principal component analysis method in predicting stock prices on Tehran Stock Exchange. Physica A: Statistical Mechanics and Its Applications, 438, 178-187. https://doi.org/10.1016/j.physa.2015.06.033

Zhang, G., Patuwo, B. E., \& Hu, M. Y. (1998). Forecasting with artificial neural networks: The state of the art. International Journal of Forecasting, 14(1), 35-62. https://doi.org/10.1016/S0169-2070(97)00044-7 